\title{
From Brexit to Biden: What Responses to National Outcomes Tell Us About the Nature of Relief
}

\author{
Social Psychological and \\ Personality Science \\ $1-10$ \\ (C) The Author(s) 2021 \\ (c) (i) (5) \\ Article reuse guidelines: \\ sagepub.com/journals-permissions \\ DOI: I0.1 I 177/I94855062। I0667I2 \\ journals.sagepub.com/home/spp
}

(SAGE

\author{
Sara Lorimer' ${ }^{(D}$, Teresa McCormack', Agnieszka J. Jaroslawska', \\ Christoph Hoerl', Sarah R. Beck ${ }^{3}$, Matthew Johnston', \\ and Aidan Feeney
}

\begin{abstract}
Recent claims contrast relief experienced because a period of unpleasant uncertainty has ended and an outcome has materialized (temporal relief) - regardless of whether it is one's preferred outcome - with relief experienced because a particular outcome has occurred, when the alternative was unpalatable (counterfactual relief). Two studies $(N=993)$, one run the day after the United Kingdom left the European Union and one the day after Joe Biden's inauguration, confirmed these claims. "Leavers" and Biden voters experienced high levels of relief, and less regret and disappointment than "Remainers" and Trump voters. "Remainers" and Trump voters showed an effect of precursor, experiencing little relief about the outcome that had occurred but stronger relief that a decision had been implemented. Only Trump voters who believed the election was over showed this precursor effect. Results suggest at least two different triggering conditions for relief and indicate a role for anticipated relief in voting behavior.
\end{abstract}

\section{Keywords}

relief, regret, Brexit, Presidential election, counterfactual emotions

Although relief is a commonly experienced emotion, it remains understudied by psychologists. Recent theoretical accounts of relief (Deutsch et al., 2015; Hoerl, 2015; Sweeny \& Vohs, 2012) hold that it is experienced under two different circumstances: when an aversive event (e.g., a painful procedure) ends, or on learning that an undesirable outcome has been avoided (e.g., finding out that one hasn't failed an exam). Following Hoerl (2015), we will refer to relief occurring after an unpleasant experience has ended as temporal relief and relief occurring on learning that an undesirable outcome has been avoided as counterfactual relief. Several accounts of relief make predictions about its function. Whereas the function of counterfactual relief is said to relate to its effects on subsequent decision making, the function of temporal relief has been linked to the effect of its anticipation on people's willingness to undergo unpleasant but ultimately beneficial experiences (Hoerl, 2015; Sweeny \& Vohs, 2012). Despite this recent psychological theorizing about different precursors and functions of relief, there is little empirical evidence of a distinction, or exploration of its usefulness in understanding people's experience of the social world. We aim to redress this imbalance between theory and evidence.

To our knowledge, the only relevant evidence comes from Sweeny and Vohs's (2012) laboratory demonstration that counterfactual and temporal relief have different psychological consequences. Although this is important preliminary evidence that counterfactual relief can be dissociated from temporal relief, there are unanswered questions. Specifically, to what extent can dissociations be observed outside of controlled laboratory settings? Can this distinction help us make sense of mixed emotions following complex real-world events? What is the relation between each relief type and the contrasting counterfactual emotions of disappointment and regret? Whereas disappointment may be experienced when an outcome is not as we would have wished, regret is typically experienced when we are responsible for the decision that led to that bad outcome (Zeelenberg et al., 1998). Due to the nature of the real-world events we studied, disappointment is likely the most appropriate comparison emotion. On the contrary, relief is frequently treated as an antonym of regret (e.g., Coricelli et al., 2005; Weisberg \& Beck, 2012) and it is often assumed that the experience of regret precludes the

\footnotetext{
'Queen's University Belfast, UK

${ }^{2}$ University of Warwick, Coventry, UK

${ }^{3}$ University of Birmingham, UK

Corresponding Author:

Aidan Feeney, School of Psychology, Queen's University Belfast, University

Road, Belfast BT7 INN, UK.

Email: a.feeney@qub.ac.uk
} 
experience of relief. Thus, we compared both disappointment and regret with relief. As we will explore, it is possible that counterfactual and temporal relief may have different relations with regret and disappointment.

\section{Relief and Political Events}

Our primary aim in this article is to examine whether the distinction between counterfactual and temporal relief helps us to understand people's feelings at the end of two drawn-out political events. By studying the emotions experienced by people following the conclusion of these events, we hoped to provide additional evidence for the distinction between relief precursors. Using divisive political events meant that we could examine emotional responses to shared events as a function of whether people had voted for or against the outcome. Arguably, this homogeneity of experience provides a degree of quasi-experimental control not possible in studies of emotional responses to decisions that have relied on participants recalling idiosyncratic life events (e.g., studies of regret and disappointment by Gilovich \& Medvec, 1994 and Zeelenberg et al., 1998). We also aimed to examine the relation between people's regret and disappointment about those events, and their feelings of both temporal and counterfactual relief.

Our studies also serve to broaden the range of emotions considered relevant to an understanding of political psychology. Work on regret in voters suggests that it reveals the extent to which their vote was discordant with the voter's underlying preferences (Blais \& Kilibarda, 2016). In this vein, voter regret was the topic of much speculation following the Brexit referendum (see Curtice, 2018). On the contrary, experiencing less regret after voting for an election-winner has been suggested as a psychological benefit of backing the winner, also known as a "bandwagon effect" (Blais \& Kilibarda, 2016). Although studying voter relief may be equally revealing with respect to voters' motivations in voting, to our knowledge, ours are the first studies to explore relief experienced in response to the outcomes of national polls or political processes.

The absence of research on relief in such contexts is striking given that a dominant model of the role of emotions in political psychology emphasizes the importance of fear and anxiety in determining political attitudes and behavior (Brader \& Marcus, 2013; Marcus et al., 2000). Indeed, anxiety is associated with the extent to which people rely on political predispositions versus situational cues when forming political judgments (Brader, 2005; Marcus et al., 2005; Vasilopoulou \& Wagner, 2017; but see Ladd \& Lenz, 2008). Under at least one account (Deutsch et al., 2015), relief is always preceded by a period of worry or anxiety. Thus, to the extent that people experience anxiety during prolonged and uncertain political processes, relief is likely to be a common feature when such processes end and merits attention on that basis alone. Moreover, based on arguments that the function of temporal relief is related to its anticipation (Hoerl, 2015; Sweeny \& Vohs, 2012), the study of relief experienced when political uncertainty ends may shed light on why some voters cross party lines and vote in accordance with situational cues and against their political predispositions. Although we did not examine voters' experiences of anxiety prior to outcomes being known, in Study 2 we examined whether relief experiences differ among voters with similar political predispositions, dependent on whether their votes crossed party lines.

\section{The Current Studies}

The social events that we studied were Brexit in the United Kingdom and the 2020 U.S. Presidential Election. The United Kingdom left the European Union (EU) on January 31, 2020. The country had been evenly divided, between pro-Brexit "Leavers" and anti-Brexit "Remainers," over the decision about whether and how to honor the result of the 2016 EU referendum (NatCen Social Research, 2020). The (largely) pro-Brexit Conservative party won the general election in December 2019 and a parliamentary decision to leave was quickly implemented. Similarly, following a bitter, closely fought election in November 2020, and a highly controversial intervening period during which the results were contested, Joe Biden was inaugurated as U.S. President on January 20, 2021. Consideration of the drawn-out nature of such political events and the polarized perspectives on their outcomes led us to formulate two hypotheses based on the distinction between temporal and counterfactual relief. First, there may be two different reasons to feel relief about an outcome: that it has finally materialized thereby ending uncertainty or anxiety (temporal relief), or that this particular outcome has materialized, when the alternative was perceived to be relatively worse (counterfactual relief). Second, because of the possibility that relief can have a purely temporal precursor, one might simultaneously feel relief that an outcome has finally occurred yet experience regret or disappointment that the outcome itself was worse than the alternative.

To test these hypotheses, we conducted one study the day after the United Kingdom left the EU and another the day after Biden's inauguration. We asked participants about the degree to which they felt several emotions, including relief, regret, and disappointment that (a) this stage of Brexit or the U.S. Presidential Election was over and (b) the political process had produced the outcome that it had. We predicted Remainers and Trump voters would indicate low levels of counterfactual relief and high levels of regret and disappointment about the outcome of the political process but at least moderate levels of temporal relief that the event was over. Leavers and Biden voters, in contrast, were predicted to indicate high levels of both types of relief and low levels of regret and disappointment. 
Table I. Demographic Information for Study I.

\begin{tabular}{llll}
\hline Voter-group & \multicolumn{1}{c}{ Leave voters } & Remain voters & No vote \\
\hline $\mathrm{n}$ & $124(73.4 \%$ female $)$ & $247(69.6 \%$ female $)$ & $126(70.0 \%$ female $)$ \\
$M_{\text {age(years) }}(\mathrm{SD})$ & $43.1(13.0)$ & $36.5(10.8)$ & $29.0(8.94)$ \\
\hline
\end{tabular}

Note. Three participants were excluded as they did not disclose their vote. The main analysis of Study I included only participants who voted $(\mathrm{n}=37 \mathrm{I})$. Given the exclusion of participants, a post hoc power analysis was performed on the observed effects for both studies. These are reported in the Supplemental Online Materials as are data from all participants on all measures which are accessible at the following link: https://osf.io/dw4ft/.

\section{Study I}

\section{Method}

Participants. In total, 500 adult participants were recruited via Prolific (https://www.prolific.co/; see Table 1 for demographic information). The sample size was based on an a priori power analysis conducted using G*Power 3 (Faul et al., 2007) to test analysis of variance (ANOVA) main effects and interactions with medium effect size $\left(\eta_{\mathrm{p}}^{2}=.06\right)$ and alpha level of .05 (see Supplemental Online Materials for further details). Results showed a sample of 206 was required to achieve a power of .95. Given that approximately $50 \%$ of the U.K. population voted in the referendum (Vesey-Byrne, 2020), this number was doubled and then rounded up to $N=500$ to account for possible missing/incomplete data. As per voting criteria, only those residing in the United Kingdom or in a British Overseas Territory were eligible to take part. The study took approximately 4 min to complete, and participants received $£ 0.40$ (GBP) for their participation. Ethical approval for both studies was granted by the Research Ethics Committee of the first author's university.

Materials and Procedure. Participants completed the questionnaire on February 1, 2020, the day after the United Kingdom legally left the EU. The full text of the questionnaires used in each study is reproduced in the Supplemental Online Materials. Following demographic questions, participants were asked how they voted in the 2016 EU referendum. Participants were then provided with a description of the current state of the Brexit process and asked to rate the extent to which they felt six emotions (regretful, relieved, triumphant, excited, disappointed, and fearful) about two aspects of the EU referendum. Specifically, participants were asked a question focused on the ending of the period of uncertainty, that is, that this stage of Brexit was over, and a decision had been implemented to leave the EU, followed by a question focused on the outcome itself, namely, the decision to leave the EU. Participants rated each of the six emotions using a 100-point visual analogue scale ranging from not at all to extremely. Ratings for the relief probe following each question were used as measures of temporal and counterfactual relief, respectively. Following this, those participants who indicated that they voted in the referendum were asked whether they regretted how they voted. Participants who indicated that they did not vote but were eligible to do so were asked whether they regretted not voting. Responses to both questions probing regret were given on a 100-point visual analogue scale anchored No, not at all to the left and Yes, a lot to the right.

\section{Results}

Emotion ratings by voter-group (Remainer, Leaver) and question focus (stage over, decision to leave) can be seen in Figure 1.

A mixed ANOVA with emotion and question focus as within-subject factors, and voter-group as a betweensubjects factor, revealed a three-way interaction between question focus, emotion, and voter-group, $F(1.89,696)=$ $19.4, p<.001, \eta_{\mathrm{p}}^{2}=.05$. To explore the significant interaction, separate ANOVAs with emotion and question as factors were conducted for each of the voter-groups. Note, for both studies, post hoc tests have been Bonferronicorrected.

Leavers. Results revealed a main effect of emotion, $F(2$, 246) $=132, p<.001, \eta_{\mathrm{p}}^{2}=.52$, such that Leavers felt significantly more relief than regret $\left(M_{\text {difference }}=48.2,95 \%\right.$ confidence interval $[\mathrm{CI}]=[40.0,56.8], p<.001)$ or disappointment $\left(M_{\text {difference }}=52.3,95 \% \mathrm{CI}=[43.6,52.3], p<\right.$ $.001)$. No other effects were significant.

Remainers. Results indicated a main effect of emotion in Remainers, $F(1,246)=265, p<.001, \eta_{\mathrm{p}}^{2}=.52$. Remainers felt significantly less relief than regret $\left(M_{\text {difference }}\right.$ $=50.0,95 \% \mathrm{CI}=[43.8,56.2], p<.001)$ or disappointment $\left(M_{\text {difference }}=52.5,95 \% \mathrm{CI}=[46.3,58.7], p<.001\right)$. As predicted, a significant interaction between emotion and question was observed, $F(2,492)=74.9, p<.001, \eta_{\mathrm{p}}^{2}=.23$.

A series of $t$ tests indicated that the interaction between emotion and question focus was driven by differing effects of the question focus variable on different emotions. Specifically, Remainers felt much more relieved about the current stage of Brexit being over than they did about the decision to leave the EU, $M_{\text {difference }}=20.6,95 \% \mathrm{CI}=$ $[15.3,25.8], t(246)=10.5, p<.001, d=0.67$. Conversely, these participants felt more regretful about the decision to 


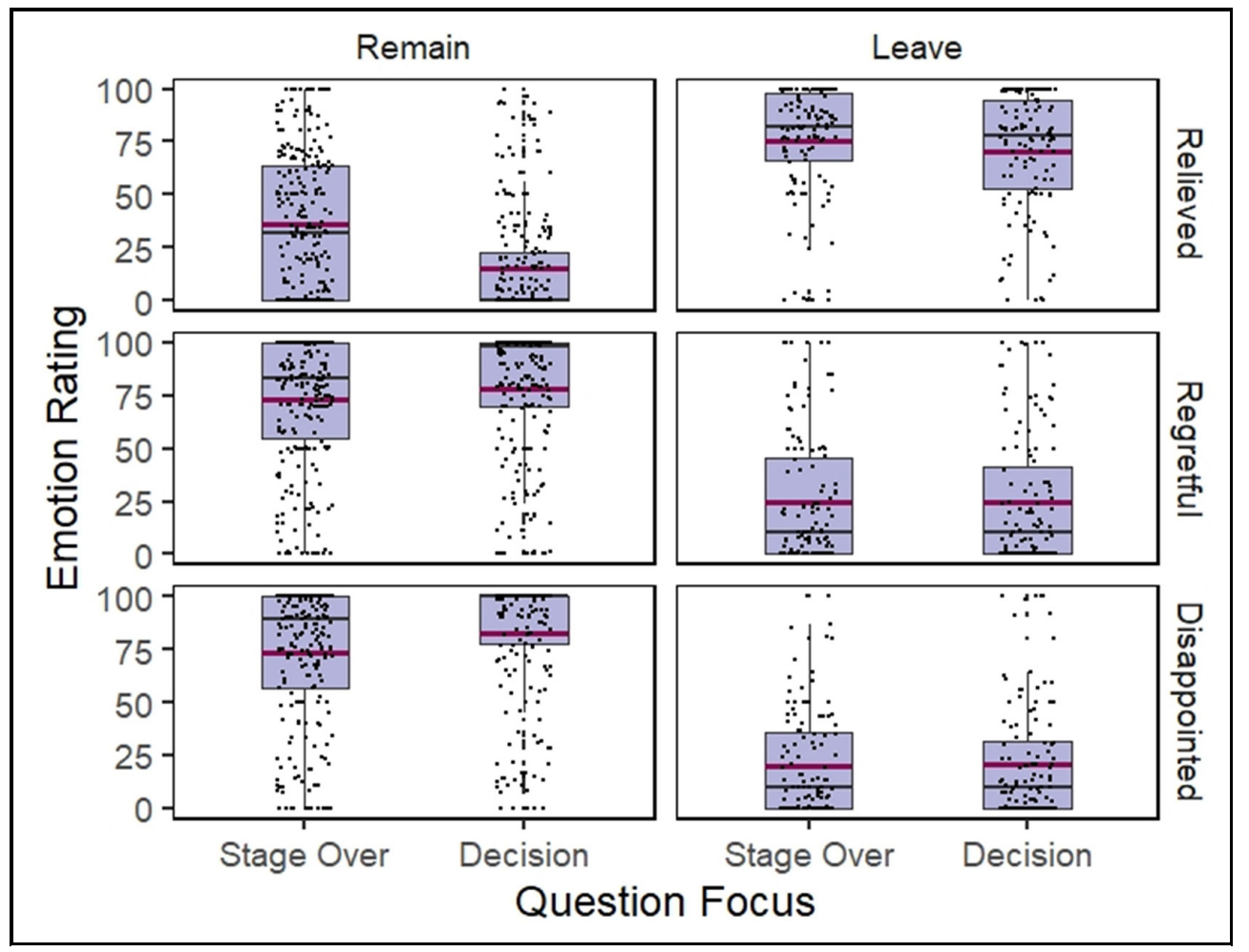

Figure I. Distribution of Emotion Ratings from Study I by Voter-Group and Emotion Note. Points are individual scores; red lines indicate mean; black lines indicate median; boxes depict first and third quartiles; and whiskers depict maximum and minimum values within 1.5 times the interquartile range.

leave the EU than they did about the current stage of Brexit being over, $M_{\text {difference }}=5.31,95 \% \mathrm{CI}=[.0510 .6]$, $t(246)=3.54, p<.001, d=0.23$. A similar pattern was observed in their disappointment ratings, $M_{\text {difference }}=$ $9.42,95 \% \mathrm{CI}=[4.17,14.7], t(246)=5.09, p<.001, d=$ 0.32 .

Comparing Remainers to Leavers. Leavers felt more relief than Remainers about both the decision to leave the EU, $M_{\text {difference }}=54.9,95 \% \mathrm{CI}=[49.2,60.6], t(369)=19.0, p$ $<.001, d=2.09$, and the current stage of Brexit being over, $M_{\text {difference }}=39.5,95 \% \mathrm{CI}=[32.8,46.3], t(369)=$ 11.6, $p<.001, d=1.27$. Conversely, Remainers felt more regret than Leavers about both the decision to leave the EU, $M_{\text {difference }}=53.9,95 \% \mathrm{CI}=[47.2,60.6], t(369)=$ $15.8, p<.001, d=1.73$, and the current stage of Brexit being over, $M_{\text {difference }}=48.2,95 \% \mathrm{CI}=[41.5,54.8]$, $t(369)=14.2, p<.001, d=1.57$. Similarly, Remainers felt more disappointment than Leavers regarding both the decision to leave the EU, $M_{\text {difference }}=62.0,95 \% \mathrm{CI}=$ $[51.0,62.0], t(369)=19.6, p<.001, d=2.16$, and the current stage of Brexit being over, $M_{\text {difference }}=53.1,95 \% \mathrm{CI}$ $=[42.0,64.2], t(369)=15.7, p<.001, d=1.73$.
Referendum Vote Regret. A Mann-Whitney $U$ test, $U=$ $19,049, p<.001, r=.24$, indicated that Leavers reported higher vote regret ratings $(M=21.3,95 \% \mathrm{CI}=[15.5$, 27.0]) than Remainers $(M=7.91,95 \% \mathrm{CI}=[5.36,10.5])$.

\section{Discussion}

Relief was the dominant emotion among Leavers, while regret and disappointment dominated over relief among Remainers. As predicted, unlike Leavers, Remainers reported greater relief when asked about the current stage of Brexit being over, while their regret and disappointment levels were higher when asked about the decision to leave. In line with previous research (e.g., British Election Study, 2016), Leavers reported greater vote regret than Remainers.

\section{Study 2}

The results of Study 1 confirm our hypotheses that the emotional responses of voters on the losing side of Brexit would distinguish between temporal relief, that an outcome has materialized thus ending a period of anxiety, and counterfactual relief, that the outcome was better than it might have been. As predicted, Remainers experienced moderate 
levels of temporal relief relative to their low levels of counterfactual relief. In Study 2, we sought to generalize this finding to U.S. voters' reactions to the results of the 2020 American Presidential election. Unlike the Brexit referendum, U.S. elections tend to play out along party lines with Republican- and Democrat-supporting voters encouraged to vote according to their political predispositions. Depending on voting patterns, this may allow us to examine relief among voters who voted either in accordance with or contrary to those predispositions. Furthermore, as it became clear in the aftermath of the election that some voters would not accept the result, we also asked participants whether they thought that the election was over. We hypothesized that voters on the losing side would experience more temporal than counterfactual relief only if they considered the election to be over.

\section{Method}

Participants. In total, 501 adult participants were recruited via Prolific (https://www.prolific.co/; see Table 2 for demographic information). The same determination of sample size as Study 1 was used (see Supplemental Online Materials) given that a similar proportion $(\sim 60 \%)$ of the U.S. population voted in the election (Desilver, 2021). Only Americans residing in the United States of America were eligible to participate. Participants received the U.S. dollar equivalent of $£ 0.40$ (GBP) for their participation.

Materials and Procedure. Participants completed the questionnaire on January 21, 2021 (the day after the Presidential inauguration). Following demographic questions, participants were asked how they voted in the 2020 Presidential election. Participants were then provided with a description of the position after the inauguration and asked to rate the extent to which they felt the same emotions as used in Study 1: (a) about the Presidential election being over and then (b) about Joe Biden having been confirmed as the winner of Presidential election.

Following this, and using the same scale as in Study 1, those participants who indicated that they voted in the election were asked whether they regretted how they voted. Participants who indicated that they did not vote but were eligible to do so were asked whether they regretted not voting in the election. Finally, participants were asked to indicate whether they agreed that the 2020 Presidential election was over.

\section{Results}

To test our primary hypotheses about temporal and counterfactual relief, we compared the emotion ratings of Biden voters with Trump voters. Emotion ratings per voter-group
Table 2. Demographic Information for Study 2.

\begin{tabular}{lll}
\hline \multirow{2}{*}{ Candidate voted for } & \multicolumn{2}{c}{ Political predisposition } \\
\cline { 2 - 3 } & \multicolumn{1}{c}{ Democrat } & \multicolumn{1}{c}{ Republican } \\
\hline Biden & & \\
$n$ & $232(60.8 \%$ female $)$ & $36(63.9 \%$ female $)$ \\
$M_{\text {age(years) }}(S D)$ & $32.4(11.8)$ & $32.8(8.6)$ \\
Trump & & $181(49.7 \%$ female $)$ \\
$n$ & $3(66.7 \%$ female $)$ & $37.7(13.2)$ \\
$M_{\text {age(years) }}(S D)$ & $27.7(13.3)$ & $6(0 \%$ female $)$ \\
$\begin{array}{l}\text { Other } \\
n\end{array}$ & $1(100 \%$ female $)$ & $29.7(4.2)$ \\
$M_{\text {age(years) }}(S D)$ & $29.0(\mathrm{NA})$ & $23(47.8 \%$ female $)$ \\
No vote & $14(42.9 \%$ female $)$ & $29.5(11.5)$ \\
$n$ & $22.4(6.3)$ & \\
$M_{\text {age(years) }}(S D)$ &
\end{tabular}

Note. We recruited approximately equal number of participants identifying on Prolific as Democrat or Republican. Five participants were excluded as they did not disclose their vote; 30 Republican participants (27 Trump voters, 3 "no vote" participants) reported that they did not believe the election was over. The main analysis of Study 2 included only participants who believed the election was over, and voted for Biden $\left(n=268,57.5 \%\right.$ female, $M_{\mathrm{age}}=$ 32.4 years, $\left.S D_{\text {age }}=11.4\right)$ or Trump $\left(n=157,49 \%\right.$ female, $M_{\text {age }}=36.9$ years, $\left.S D_{\text {age }}=12.8\right) . N A=$ not applicable.

(Biden, Trump) and question focus (election over, election outcome) can be seen in Figure 2.

A mixed ANOVA with voter-group as a betweensubjects factor and emotion and question focus as withinsubject factors revealed a significant three-way interaction between question focus, emotion, and voter-group; $F(1.84$, $777)=12.6, p<.001, \eta_{\mathrm{p}}^{2}=.03$. Separate ANOVAs with emotion and question as factors were conducted for each of the voter-groups.

Biden Voters. Results revealed a main effect of emotion, $F(1.25,332)=1,990, p<.001, \eta_{\mathrm{p}}^{2}=.88$, with Biden voters reporting more relief than regret $\left(M_{\text {difference }}=83.2\right.$, $95 \%$ CI $=[79.1,87.2], p<.001)$ or disappointment $\left(M_{\text {difference }}=80.5,95 \% \mathrm{CI}=[76.1,85.0], p<.001\right)$, and more disappointment than regret $\left(M_{\text {difference }}=2.63,95 \%\right.$ $\mathrm{CI}=[0.88,4.37], p=.001)$.

Trump Voters. Results indicated a main effect of emotion, $F(1.64,255)=42.8, p<.001, \eta_{\mathrm{p}}^{2}=.22$, with Trump voters reporting more disappointment than relief $\left(M_{\text {difference }}=\right.$ $31.3,95 \% \mathrm{CI}=[20.8,41.7], p<.001)$ or regret $\left(M_{\text {difference }}\right.$ $=27.0,95 \% \mathrm{CI}=[20.2,33.7], p<.001)$. As predicted, a significant interaction between emotion and question focus was observed in Trump voters, $F(1.84,286)=12.5, p<$ $.001, \eta_{\mathrm{p}}^{2}=.074$. Examination of the means involved in this interaction revealed that Trump voters felt significantly more relief that the election was over $(M=42.5,95 \% \mathrm{CI}$ 


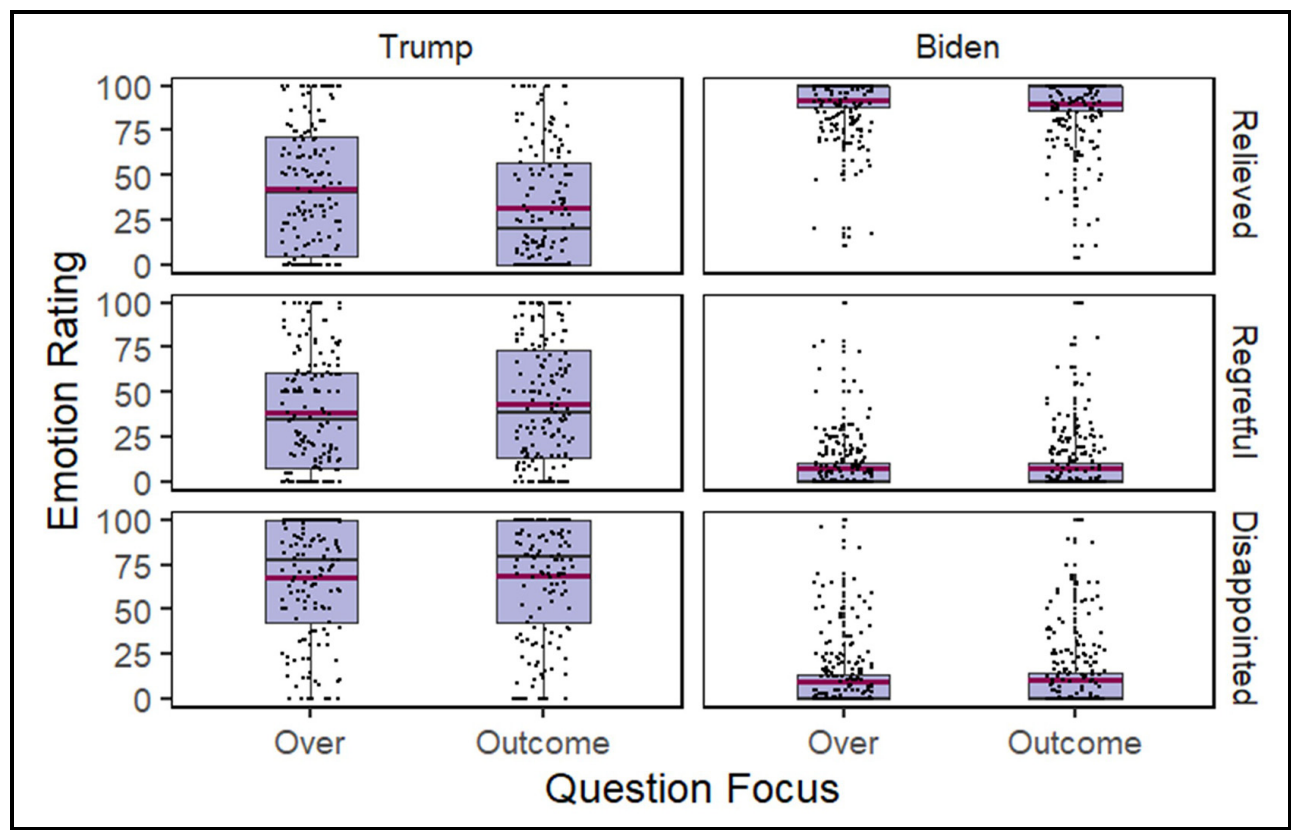

Figure 2. Distribution of Emotion Ratings from Study 2 by Voter-Group and Emotion

Note. Points are individual scores; red lines indicate mean; black lines indicate median; boxes depict first and third quartiles; and whiskers depict maximum and minimum values within 1.5 times the interquartile range. Only Trump voters who believed the election was over are included.

$=[36.9,48.0])$ than about its outcome, $M=31.5,95 \% \mathrm{CI}$

$=[26.4,36.7], t(156)=4.71, p<.001, d=0.38$.

Trump Voters Versus Biden Voters. Biden voters felt more relief than Trump voters about both the election being over, $U$ $=36,967, p<.001, r=.76$, and the outcome of the election, $U=38,714, p<.001, r=.84$. Conversely, Trump voters felt more regret than Biden voters about both the election being over, $U=8,454, p<.001, r=.60$, and its outcome, $U=6,904, p<.001, r=.67$. Similarly, Trump voters felt more disappointment than Biden voters about both the election being over, $U=3,541, p<.001, r=.76$, and its outcome, $U=3,849, p<.001, r=.82$.

Differences Between Republican Voters. To determine whether election-over beliefs affected differences between temporal and counterfactual relief, we carried out an exploratory mixed ANOVA on the ratings of participants identifying as Republican. Group (Biden voters $[n=36]$, Trump voters who believed the election was over $[n=154]$, Trump voters who did not believe the election was over $[n=27]$ ) was included as a between-subjects factor and emotion (relief, regret, disappointment) and question focus (election over, election outcome) as within-subject factors. Emotion ratings for Republican voters are presented in Figure 3.

The results contained significant two-way interactions between emotion and group, and emotion and question focus. The two-way interaction between emotion and group, $F(3.46,369.9)=53.1, p<.001, \eta_{\mathrm{p}}^{2}=.33$, reveals differences in the dominant emotions of each group of Republican voters and differences in emotions between groups. Specifically, Biden-voting Republicans reported significantly more relief than regret or disappointment (both $M_{\text {difference }} \geqslant 65.6,95 \% \mathrm{CI}=[\geqslant 42.2, \leqslant 89.7]$, both ps $<.001)$, Trump voters who believed the election was over reported more disappointment than regret or relief (both $M_{\text {difference }} \geqslant 27.3,95 \%$ CI $=[\geqslant 10.1, \leqslant 44.4]$, both $p$ s $<.001)$, and Trump voters who did not believe the election was over reported more disappointment than regret or relief (both $M_{\text {difference }} \geqslant 49.4,95 \%$ CI $=[\geqslant 22.5$, $\leqslant 108.5$ ], both $p \mathrm{~s}<.001)$ and more regret than relief $\left(M_{\text {difference }}=32.1,95 \% \mathrm{CI}=[5.10,59.0], p=.005\right) . \mathrm{In}$ addition, Biden voters reported more relief $\left(M_{\text {difference }} \geqslant\right.$ $42.3,95 \% \mathrm{CI}=[\geqslant 25.1, \leqslant 92.9]$ ) and less regret (both $\left.M_{\text {difference }} \geqslant 28.1,95 \% \mathrm{CI}=[\geqslant 5.54, \leqslant 52.8]\right)$ or disappointment (both $M_{\text {difference }} \geqslant 53.8,95 \%$ CI $=[\geqslant 36.6$, $\leqslant 101.5]$ ) than either of the other groups (all $p \mathrm{~s}<.01$ ). Trump voters who believed the election was over reported more relief $\left(M_{\text {difference }}=27.0,95 \% \mathrm{CI}=[7.60,46.3], p<\right.$ $.001)$ and less disappointment $\left(M_{\text {difference }}=32.1,95 \% \mathrm{CI}\right.$ $=[5.10,59.0], p=.003)$ than Trump voters who did not believe the election was over.

The two-way interaction between emotion and question focus, $F(1.87,390.9)=6.77, p=.002, \eta_{\mathrm{p}}^{2}=.031$, is driven by the effect of question focus on relief but not regret or disappointment ratings. Participants reported more relief when asked about the election being over than about the outcome $\left(M_{\text {difference }}=8.56,95 \%\right.$ CI $=[1.95,15.2]$, $p=.002)$. 


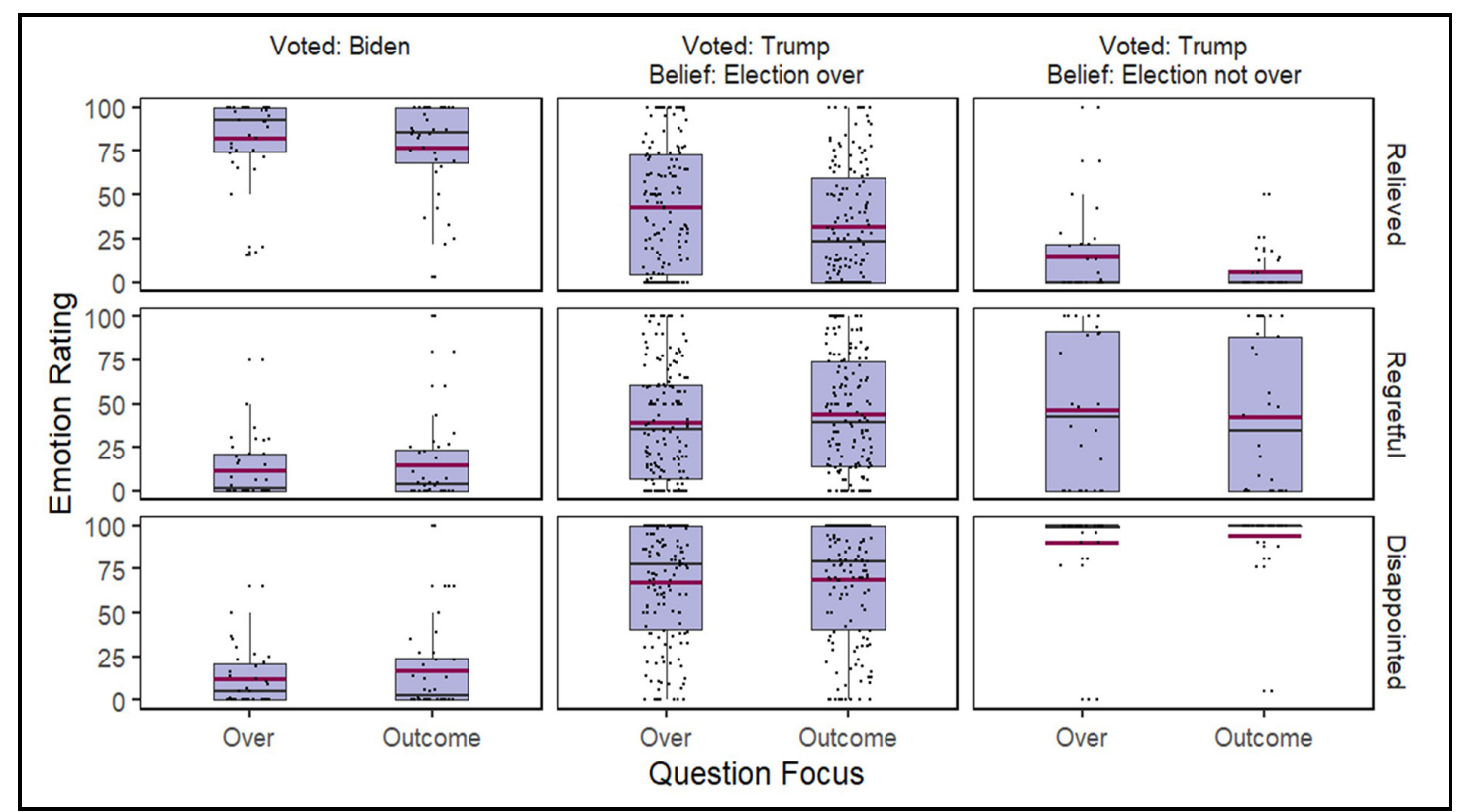

Figure 3. Distribution of Emotion Ratings of Republicans by Vote and Election-Over Beliefs

Note. Points are individual scores; red lines indicate mean; black lines indicate median; boxes depict first and third quartiles; and whiskers depict maximum and minimum values within 1.5 times the interquartile range.

Critical to our secondary hypothesis, exploration of the non-significant three-way interaction reveals that only Republicans who voted for Trump and believed the election was over reported significantly more relief that the election was over than about the outcome $\left(M_{\text {difference }}=\right.$ $11.1,95 \% \mathrm{CI}=[3.77,18.5], p<.001)$. Within groups, no other emotion ratings differed significantly due to question focus.

Vote Regret. A Mann-Whitney $U$ test indicated significant variation in vote regret between Biden voters and Trump voters who believed the election was over, $U=16,883, p$ $<.001, r=.20$. Trump voters reported feeling more regretful about how they voted $(M=13.7,95 \% \mathrm{CI}=$ $[9.52,18.0])$ than Biden voters $(M=3.28,95 \% \mathrm{CI}=$ $[1.93,4.63])$. When only Republican participants are considered, Welch's ANOVA showed a significant main effect of group, $F(2,80.6)=20.23, p<.001, \eta_{p}^{2}=.033$. Post hoc tests indicated that among those Republicans who believed the election was over, Biden voters reported significantly more vote regret than Trump voters $\left(M_{\text {difference }}=\right.$ $8.31,95 \% \mathrm{CI}=[1.02,15.6], p=.022)$.

\section{Discussion}

The results of Study 2 indicate that relief is the dominant emotion among Biden voters (regardless of party affiliation), while among Trump voters, disappointment is felt more acutely than relief or regret. Unlike Biden voters, Trump voters reported feeling more relieved that the election was over than about the outcome. Importantly, this result is confined to Trump voters who believed the election was over. Trump voters who did not believe the election was over experienced extremely low levels of relief about both aspects of the process.

\section{General Discussion}

Those who voted to remain in the EU in the 2016 Brexit referendum expressed high levels of regret and disappointment and low levels of relief about the parliamentary decision to leave the EU. Strikingly, Remainers expressed much higher levels of relief that a decision had been made and implemented than that the implemented decision was to leave, a pattern consistent with temporal relief occurring in the absence of counterfactual relief. Contrastingly, Leavers expressed high levels of relief and low levels of regret and disappointment, both that the parliamentary decision to leave had been made and implemented, and that the decision was to leave. That is, this group showed a pattern suggesting both temporal and counterfactual relief. The details of these two patterns were replicated among voters in the 2020 U.S. Presidential election. Trump voters expressed high levels of disappointment but lower levels of relief about the outcome of the election, and more relief that the electoral process was over than that Biden had won. Biden voters, on the contrary, expressed high levels of relief and very low levels of disappointment and regret about the outcome of the election and the fact that their preferred candidate had won. These results are consistent 
with our hypotheses that one can feel relief about different aspects of an outcome, and that regret, disappointment, and relief can be felt simultaneously about different aspects of the same outcome. Thus, in demonstrating that people, following real-world events, may experience different levels of temporal relief - about a period of uncertainty ending when compared with counterfactual relief-about the nature of the outcome itself - the results offer strong and novel empirical support for distinctions between different types of precursor to relief (Deutsch et al., 2015; Hoerl, 2015; Sweeny \& Vohs, 2012).

It is striking that we have observed the same pattern of results in two different Western democracies and in relation to two different types of political events (for differences between referenda and national elections, see LeDuc, 2002). Moreover, while the liberal side lost the Brexit referendum, the conservative side lost the 2020 U.S. election. Yet in both cases, voters on the losing side reported significantly stronger levels of relief that the process was over than they did about the outcome. These differences between the contexts that have given rise to very similar sets of results speak to the generality of our findings. However, there are important differences between the two study contexts. For example, in Study 1, vote regret was higher among participants who voted for Brexit and were thus on the winning side, whereas in Study 2, it was higher among Trump voters who were on the losing side. In the case of Brexit, it is possible that regretted votes are due to a mismatch between voting behavior and underlying preferences (Blais \& Kilibarda, 2016). Alternatively, as regret has the potential to emerge over time (e.g., Davison \& Feeney, 2008), vote regret may have increased in the considerable period that had passed since the referendum. The finding that Remainers in Study 1 experienced higher levels of regret (about both the outcome of the process and that it was over) than Trump voters in Study 2 may be explained in the same way: Whereas Trump voters were focused on the outcome of the recent election leading to higher levels of disappointment than regret, Brexit-related regret among Remainers may have increased in the time since the referendum.

Another important difference between the studies is that in Study 2, we were able to identify a subset of voters who had voted against their political predispositions. Strikingly, relief was the dominant emotion among these voters. Interestingly, there are reasons to suspect that the winning sides in both sets of political events studied here believed that appeals to relief might prove effective in attracting voters. For example, during his campaign, Biden tweeted that he could "end the last four years of chaos" (Biden, 2020), and during the general election campaign of 2019, the Conservatives deliberately framed themselves as the party that would bring relief to the nation (Behr, 2020), while warning that their biggest rival, Labour, would offer no such relief. Indeed, the Conservatives fought the election on the slogan "Get Brexit done." Regardless of whether they supported Donald Trump or wished to remain in the EU, voters were invited to anticipate the temporal relief they would feel once Biden or the Conservative party had won the election thus bringing a period of national anxiety and uncertainty to an end. Our results show that Republicans who voted for Biden would have been correct in anticipating temporal relief once a national decision had been made. Interestingly, Biden-voting Republicans expressed more regret about their vote than Trump-voting Republicans, perhaps indicating a psychological cost to voting against one's political predispositions.

Although the function of relief is not well understood (Hoerl, 2015), it has been suggested that the function of temporal relief in particular may be related to its anticipation (Hoerl, 2015; Sweeny \& Vohs, 2012). That is, people may be nudged into undergoing aversive but ultimately beneficial experiences by anticipating the temporal relief that will occur when the experience has ended. Our results are consistent with the possibility that Republicans who ended up voting for Biden (and presumably felt anxious about the possibility of a second Trump term) may have been encouraged to vote against their political predispositions by invitations to imagine the relief they would feel when the previous "years of chaos" had ended. We note that there is an analogy to be made between temporal relief experienced at the end of an unpleasant event and negative reinforcement in operant conditioning (see Deutsch et al., 2015, for further discussion). Future work might examine whether the relief experienced among those who vote against their political predispositions might reinforce this kind of voting pattern and lead to them voting across party lines in subsequent elections. Although further research is needed to directly measure both anxiety and anticipatedas well as experienced-relief in response to significant social and political events, our results suggest that in countries with divided electorates, due to relief's association with anxiety (Deutsch et al., 2015), appeals to anticipated relief may lead to voters crossing ideological lines.

\section{Declaration of Conflicting Interests}

The author(s) declared no potential conflicts of interest with respect to the research, authorship, and/or publication of this article.

\section{Funding}

The author(s) disclosed receipt of the following financial support for the research, authorship, and/or publication of this article: This research was funded by Grant RPG-2018-019 from the Leverhulme Trust.

\section{ORCID iD}

Sara Lorimer (iD https://orcid.org/0000-0003-1144-534X 


\section{Supplemental Material}

The supplemental material is available in the online version of the article.

\section{Note}

1. See https://www.cer.eu/brexit-timeline or https://commons library.parliament.uk/research-briefings/cbp-7960/ for Brexit timeline.

\section{References}

Behr, R. (2020, January 29). What having a heart attack taught me about Brexit. The Guardian. https://www.theguardian.com/ commentisfree/2020/jan/29/heart-attack-brexit-politics

Biden, J. (2020, November 1). Together, we can end the last four years of chaos. Twitter. https://twitter.com/JoeBiden/status/ 1322709944509124613

Blais, A., \& Kilibarda, A. (2016). Correct voting and post-election regret. PS: Political Science \& Politics, 49, 761-765. https: //doi.org/10.1017/S1049096516001372

Brader, T. (2005). Striking a responsive chord: How political ads motivate and persuade voters by appealing to emotions. American Journal of Political Science, 49(2), 388-405. https: //doi.org/10.1111/j.0092-5853.2005.00130.x

Brader, T., \& Marcus, G. E. (2013). Emotion and political psychology. In L. Huddy, D. O. Sears, \& J. S. Levy (Eds.), The Oxford handbook of political psychology (pp. 165-204). Oxford University Press.

British Election Study. (2016). Brexit Britain: British Election Study Insights from the post-EU Referendum wave of the BES internet panel. https://www.britishelectionstudy.com/besresources/brexit-britain-british-election-study-insights-fromthe-post-eu-referendum-wave-of-the-bes-internet-panel/ \#.XrExEfZFxPY

Coricelli, G., Critchley, H. D., Joffily, M., O’Doherty, J. P., Sirigu, A., \& Dolan, R. J. (2005). Regret and its avoidance: A neuroimaging study of choice behavior. Nature Neuroscience, $8(9)$, 1255-1262.

Curtice, J. (2018). Buyer's remorse: Has Britain changed its mind on Brexit? Political Insight, 9, 12-15. https://doi.org/10.1177/ 2041905818764700

Davison, I. M., \& Feeney, A. (2008). Regret as autobiographical memory. Cognitive Psychology, 57(4), 385-403. https://psycnet. apa.org/doi/10.1016/j.cogpsych.2008.03.001

Desilver, D. (2021, January 28). Turnout soared in 2020 as nearly two-thirds of eligible U.S. voters cast ballots for president. Pew Research Center. https://www.pewresearch.org/fact-tank/2021/ 01/28/turnout-soared-in-2020-as-nearly-two-thirds-of-eligibleu-s-voters-cast-ballots-for-president/

Deutsch, R., Smith, K. J. M., Kordts-Freudinger, R., \& Reichardt, R. (2015). How absent negativity relates to affect and motivation: An integrative relief model. Frontiers in Psychology, 6, Article 152. https://doi.org/10.3389/fpsyg.2015.00152

Faul, F., Erdfelder, E., Lang, A. G., \& Buchner, A. (2007). $G^{*}$ Power 3: A flexible statistical power analysis program for the social, behavioral, and biomedical sciences. Behavior Research Methods, 39(2), 175-191.

Gilovich, T., \& Medvec, V. H. (1994). The temporal pattern to the experience of regret. Journal of Personality and Social
Psychology, 67(3), 357-365. https://doi.org/10.1037/0022-3514. 67.3.357

Hoerl, C. (2015). Tense and the psychology of relief. Topoi, 34(1), 217-231. https://doi.org/10.1007/s11245-013-9226-3

Ladd, J. M., \& Lenz, G. S. (2008). Reassessing the role of anxiety in vote choice. Political Psychology, 29(2), 275-296. https: //doi.org/10.1111/j.1467-9221.2008.00626.x

LeDuc, L. (2002). Opinion change and voting behavior in referendums. European Journal of Political Research, 41, 711-732. https://doi.org/10.1111/1475-6765.00027

Marcus, G. E., Neuman, W. R., \& MacKuen, M. (2000). Affective intelligence and political judgment. The University of Chicago Press.

Marcus, G. E., Sullivan, J. L., Theiss-Morse, E., \& Stevens, D. (2005). The emotional foundation of political cognition: The impact of extrinsic anxiety on the formation of political tolerance judgments. Political Psychology, 26(6), 949-963. https: //doi.org/10.1111/j.1467-9221.2005.00452.x

NatCen Social Research. (2020). Should the United Kingdom remain a member of the European Union, or leave the European Union? (Asked after the referendum). https://whatukthinks.org/eu/questions/should-the-united-kingdom-remain-a-member-of-the-european-union-or-leave-the-european-unionasked-after-the-referendum/?removed

Sweeny, K., \& Vohs, K. D. (2012). On near misses and completed tasks: The nature of relief. Psychological Science, 23(5), 464-468. https://doi.org/10.1177/0956797611434590

Weisberg, D. P. \& Beck, S. R. (2012). The development of children s regret and relief. Cognition and Emotion, 26(5), 820835. https://doi.org/10.1080/02699931.2011.621933

Vasilopoulou, S., \& Wagner, M. (2017). Fear, anger and enthusiasm about the European Union: Effects of emotional reactions on public preferences towards European integration. European Union Politics, 18(3), 382-405.

Vesey-Byrne, J. (2020, November 15). Show this chart to anyone who says Brexit is the "will of the British people." Independent. https://www.indy100.com/news/brexit-leave-remain-52-48-percent-voter-turnout-electoral-register-charts-7399226

Zeelenberg, M., van Dijk, W. W., Mastead, A. S. R., \& van der Pligt, J. (1998). The experience of regret and disappointment. Cognition and Emotion, 12(2), 221-230. https://doi.org/10. 1080/026999398379727

\section{Author Biographies}

Sara Lorimer is a postdoctoral research associate in the School of Psychology at Queen s University Belfast. Her current research focuses on the nature and function of relief and her doctoral work explored time and causality in cognitive development with a specific focus on how our perception of time is influenced and altered by our beliefs about cause and effect, and agency.

Teresa McCormack is a professor in the School of Psychology at Queen s University Belfast. Her research interests lie in cognitive development, particularly the development of future thinking, counterfactual reasoning, and children's temporal cognition. 
Agnieszka Jaroslawska is a lecturer in the School of Psychology at Queen's University Belfast. She studies cognitive development across the lifespan and is particularly interested in cognitive learning difficulties, working memory and mind-wandering in children and adolescents.

Christoph Hoerl is a professor in the School of Philosophy at the University of Warwick. He works on a number of different issues in the philosophy of mind and philosophy of psychology and is particularly interested in philosophical questions about the nature of temporal experience, memory, and our ability to think about time.

Sarah Beck is a professor in the School of Psychology at the University of Birmingham. She carries out cognitive development research on how we think imaginatively about the real world. She is especially interested in how children become able to speculate about what might have been (counterfactual thinking) and how they think creatively to solve novel problems, particularly those involving tools.

Matthew Johnston is a $\mathrm{PhD}$ candidate in the School of Psychology at Queen's University Belfast interested in cognitive and emotional development. His current research focuses on the development of children's ability to attribute relief to others.

Aidan Feeney is a professor in the School of Psychology at Queen's University Belfast. Trained as a cognitive psychologist, he has broad interests in reasoning and decision making, and is particularly interested in cognitive emotions such as relief and regret and in how people think about social categories.

Handling Editor: Christopher M. Federico 